\title{
Structural characteristics of titanium coating on copper substrates
}

\author{
ARUP DASGUPTA*, AKASH SINGH, PRADYUMNA KUMAR PARIDA, R RAMASESHAN ${ }^{\dagger}$, \\ P KUPPUSAMI, S SAROJA and M VIJAYALAKSHMI \\ Physical Metallurgy Division, Indira Gandhi Centre for Atomic Research, Kalpakkam 603 102, India \\ ${ }^{\dagger}$ Surface and Nanoscience Division, Indira Gandhi Centre for Atomic Research, Kalpakkam 603 102, India
}

MS received 6 September 2010; revised 29 December 2010

\begin{abstract}
The growth characteristics of titanium films deposited on glass, silicon (100) and oxygen free high purity copper substrate using magnetron sputtering have been investigated using X-ray diffraction, electron microscopy and scratch indentation techniques. The study of interface between the titanium film and the substrate was carried out to determine coating thickness, as well as intermixing of the elements at the interface. Studies revealed that the interface is free from voids and intermixing of the film and the substrate. Microstructural and diffraction analysis showed that the Ti coating was polycrystalline and exhibited columnar growth. The Ti crystallite size varied between 24 and $58 \mathrm{~nm}$ depending on the substrate. The thickness of the films were typically about $4 \mu \mathrm{m}$. Scratch test indicated that the films are adherent and the first critical load to failure was observed to be $4.5 \mathrm{~N} \pm 2 \mathrm{~N}$.
\end{abstract}

Keywords. Coatings; sputtering; titanium; interfaces; X-ray diffraction; electron microscopy.

\section{Introduction}

Titanium and its alloys are used as structural materials in a number of industries such as aerospace and chemical (Destefani 1990; Eylon 1990), biomedical (Niinomi 1998) and nuclear (Kamachi Mudali et al 1993, 1995; Baldev et al 2000) due to the best combination of weight, strength, toughness and corrosion resistance. Its superior properties have led researchers to harness its applicability as coating on a variety of substrates, such as stainless steel (Musil et al 1996; Vieira and Nono 2004), copper (Ruder and Itzhak 1982, 1983; Bateni et al 2002), magnesium (Zhang et al 2005), silicon (Jung et al 2003; Jin et al 2009; Lee et al 2009; Oya and Kusano 2009; Zhang et al 2009) and glass (Jin et al 2009; Oya and Kusano 2009) essentially for corrosion protection of the underlying substrates or taking advantage of the biocompatibility of $\mathrm{Ti}$ with human tissues. The Ti coating has been synthesized by a variety of very high frequency plasma enhanced chemical vapour deposition (Ruder and Itzhak 1982, 1983), physical vapour deposition including magnetron sputtering (Musil et al 1996; Jung et al 2003; Vieira and Nono 2004; Zhang et al 2005, 2009; Jin et al 2009; Oya and Kusano 2009) and pack cementation (Bateni et al 2002) techniques. Ti coatings on silicon substrates are being developed for fabrication of nuclear micro-batteries in which the beta particles emitted by tritium are used to produce electron-hole pairs in silicon, similar to solar cells (Lee et al 2009). Titanium coating on copper substrates provides excellent resistance to bio-fouling to copper when exposed to water bodies for prolonged periods. Such applications are of

*Author for correspondence (arup@igcar.gov.in) profound importance as copper is the most commonly used material for heat removal in the chemical and nuclear industry due to its high thermal conductivity $\left(\sim 400 \mathrm{~W} \mathrm{~m}^{-1} \mathrm{~K}^{-1}\right)$. Titanium coating on copper can also be used for nuclear waste assay applications in which deuterium or tritium can be stored in titanium (Csikai 1987). When bombarded with accelerated deuterium ions, the trapped gases in the coating can undergo fusion and the high energy neutrons thus emitted (Ludewigt et al 2007) may be utilized to assess the amount of fissile material present in the nuclear waste from a power plant. The heat generated during the process is conducted away by the water cooled copper substrate. Most of the applications which use $\mathrm{Ti}$ on $\mathrm{Cu}$ substrate demand that the substrate-coating interface needs to withstand high stress due to the wide disparity in the thermal expansion coefficients of the two metals, viz. copper has a high coefficient of linear expansion which is equal to $16.6 \times 10^{-6} / \mathrm{K}$, whereas that of titanium is $8.6 \times 10^{-6} / \mathrm{K}$. Besides, Ti-Cu systems form various intermetallic compounds which have excellent wear resistance at temperatures as low as room temperature (Bateni et al 2002; SGTE 2004; Vieira and Nono 2004). Therefore, it is clear that, whatever the application, a study of the interface in detail is very important, as the presence of intermetallic compounds or voids can affect the adhesion and other physical properties of the coatings.

The objective of this work is to investigate the structure and interface of magnetron sputter deposited Ti coatings on oxygen free high purity copper (OFHC) substrates using electron microscopy and X-ray diffraction techniques. To the best of our knowledge, studies on interface of sputter deposited $\mathrm{Ti}$ coatings on $\mathrm{Cu}$ substrates have not been reported in the literature although reports exist on $\mathrm{Cu}-\mathrm{Ti}$ 
systems deposited on amorphous carbon substrates (Neubauera et al 2003). Hence, the present work gains importance for a technologically challenging component in the nuclear industry.

\section{Experimental}

Coatings of $\mathrm{Ti}$ were sputter deposited from a high purity $(99.99 \%)$ Ti target of $76 \mathrm{~mm}$ diameter on oxygen-free high conductivity copper (OFHC), Si and glass substrates using a custom built pulsed direct current (d.c.) magnetron sputtering. The sputtering system (Vacuum Techniques, India) consisted of a stainless steel chamber of $450 \mathrm{~mm}$ diameter and $200 \mathrm{~mm}$ deep using a sputtering gun of $\sim 75 \mathrm{~mm}$ diameter (Elangovan et al 2009, 2010). The deposition chamber was evacuated to a base pressure of $2 \times 10^{-6}$ mbar using a pumping system (Alcatel, France) consisting of a rotary and turbo molecular pumps. The flow rate of the high purity Ar was set at $50 \mathrm{sccm}$ during sputtering. A RPG-500 asymmetric bipolar pulsed d.c. power supply (MKS Instruments, USA) was used as the electrical power source for the sputter-deposition system. The substrate temperature was kept constant at $473 \mathrm{~K}$ at a base pressure of $8 \times 10^{-6}$ mbar using a halogen lamp $(800 \mathrm{~W}, 6 \cdot 3 \mathrm{~A})$ heater with a digital programmable temperature controller. Preheating of the substrate to a desired set temperature for about $0 \cdot 5 \mathrm{~h}$ was carried out. Pre-sputtering of Ti target was performed for $5 \mathrm{~min}$ prior to each deposition. Deposition was carried out at $100 \mathrm{~W}$ of plasma power using $20 \%$ duty cycle for $3 \mathrm{~h}$. The deposition conditions are listed in table 1.

Crystallographic properties of the as-deposited Ti coatings were characterized by X-ray diffraction (XRD) technique using an INEL XRG - 3000 Diffractometer at a glancing angle of incidence $(\omega)$ of $5^{\circ}$ and $\mathrm{Cu} \mathrm{K}_{\alpha 1}$ radiation. The crystallite size (coherent crystalline domains) was determined using the Scherrer formula,

$$
D=\frac{k \lambda}{\cos \theta \sqrt{B^{2}-b^{2}}},
$$

where $\lambda$ is the wavelength of the X-rays used, $k$ the correction factor, $\theta$ the diffraction angle, $B$ the full width at half maximum (FWHM) of film, and $b$ the FWHM of the instrumental broadening. The instrumental broadening was corrected

Table 1. Deposition parameters of Ti coatings.

\begin{tabular}{lc}
\hline Base pressure & $8 \times 10^{-6} \mathrm{mbar}$ \\
Operating pressure & $7.5 \times 10^{-3} \mathrm{mbar}$ \\
Substrate to target distance & $60 \mathrm{~mm}$ \\
Target voltage & $200-350 \mathrm{~V}$ \\
Substrate temperature & $473 \mathrm{~K}$ \\
Pulse power & $100 \mathrm{~W}$ \\
Duty cycle & $20 \%$ \\
Pulse frequency & $100 \mathrm{kHz}$ \\
Argon flow rate & $50 \mathrm{sccm}$ \\
\hline
\end{tabular}

using silicon standard powder received from National Physical laboratory, New Delhi. The thickness of the films was measured using DEKTAK 6 M-stylus profiler (Veeco, USA). Scotch tape adhesion test was performed routinely on the asdeposited and cyclically heat treated coatings. In addition, quantitative adhesion strength of the coatings were measured in Revet Scratch tester (CSM, Switzerland) with a continuously increasing applied normal force which was varied from 0 to $20 \mathrm{~N}$ using a Berkovich diamond indenting probe. The probe was moved with a velocity of $3 \mathrm{~mm} / \mathrm{min}$ at a loading rate of $10 \mathrm{~N} / \mathrm{min}$. A cyclic heat treatment ( 5 cycles) between 373 and $673 \mathrm{~K}$ with a heating rate of $\sim 100 \mathrm{~K} / \mathrm{min}$ and cooling rate of $\sim 9 \mathrm{~K} / \mathrm{min}$ was carried out on some of the samples to evaluate the adhesion after cyclic treatment.

The scanning electron microscopy of the coating was carried out in a Philips XL-30 ESEM scanning electron microscope (SEM) at an operating voltage of $30 \mathrm{kV}$. Transmission electron microscopy (TEM) of the cross-section sample was carried out using a Philips CM-200 analytical TEM having an acceleration voltage of $200 \mathrm{kV}$. The cross-section sample was prepared by gluing the samples with the coated surface facing each other. A section of the sandwich was mounted on a Ti slot (dimension: $2 \times 1 \times 1 \mathrm{~mm}$ ) grid as shown in figure 1 . The mounted specimen was then ground, polished in plane parallel configuration from both sides to a final thickness of $\sim 40 \mu \mathrm{m}$. It may be mentioned here that attempts to dimple the specimen failed as both $\mathrm{Cu}$ substrate and the Ti coating are highly ductile. Finally the specimen was ion milled to produce electron transparent regions.

The Ar ion sputtering yields of $\mathrm{Ti}$ and $\mathrm{Cu}$ are reported in the literature as 1.6 atoms/ion and 5.3 atoms/ion, respectively, at an ion energy of $6 \mathrm{keV}$ (Matsunami et al 1984). Such a wide difference in sputtering yields for $\mathrm{Ti}$ and $\mathrm{Cu}$ poses a considerable challenge in specimen preparation.

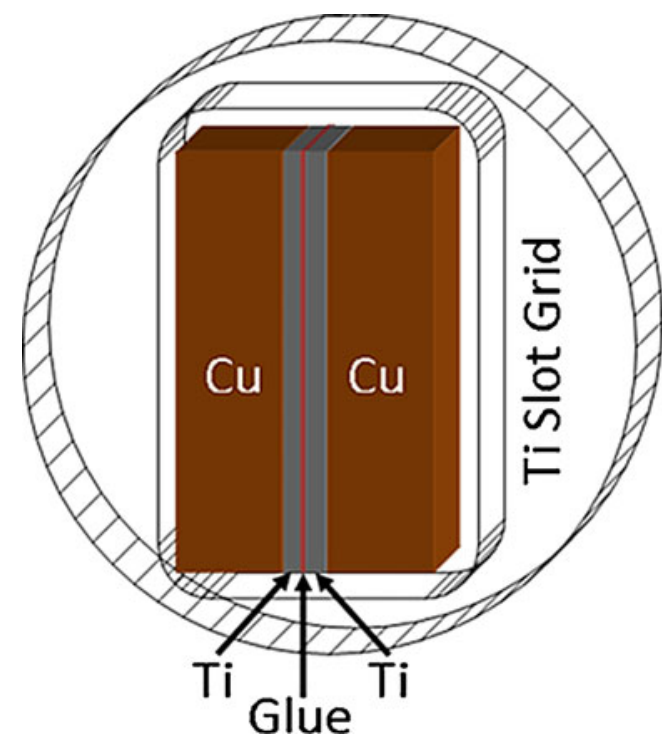

Figure 1. Schematic representation of the cross-section specimen mounting for TEM studies. 
Minimizing the incident ion angle to the surface of the specimen has been found to be an effective technique in overcoming this problem. Several trials were made using various angles of incidence and position of the cross-section with respect to beam. The optimum condition for electron transparent foil was found when the angle of incidence was $6-10^{\circ}$ and the incident beam was normal to the cross-section in oscillating mode.

\section{Results and discussion}

In order to optimize the deposition parameters as well as to understand the substrate effect, Ti films were deposited on three different substrates, viz. $\mathrm{Cu}$, glass and $\mathrm{Si}$ at $473 \mathrm{~K}$ for $3 \mathrm{~h}$. The coatings were found to have metallic lustre and thickness was about $4 \mu \mathrm{m}$ from the profilometer measurements. Figure 2 shows XRD pattern of the coatings deposited on three different substrates. The Ti coatings exhibit hcp$\mathrm{Ti}\left(\alpha\right.$-Ti) phase. There is a preferred orientation of $(00 \cdot 2)_{\alpha}$ plane normal // sample normal direction, for the coatings deposited on glass and (100) silicon substrates. However, the coatings deposited on $\mathrm{Cu}$ substrates do not show preferred orientation and intensities of the reflections closely match with those of bulk hcp-Ti reported in JCPDS (2003). The crystallite size of the coatings determined using Scherrer equation having $(10 \cdot 1)_{\alpha}$ and $(00 \cdot 2)_{\alpha}$ reflections were found to be similar and the average values of the Ti crystallite sizes deposited on $\mathrm{Cu}$, glass and $\mathrm{Si}$ substrates were found to be $58 \mathrm{~nm}, 31 \mathrm{~nm}$ and $24 \mathrm{~nm}$, respectively. As described earlier, Scherrer formula was used to evaluate size of the crystallites, and error due to contribution from strain in the nanostructured films have not been considered. The increased crystallite size on a metallic substrate than that obtained on insulating and semiconducting substrates has also been reported in our earlier work on $\mathrm{CrN}$ coatings by plasma assisted MOCVD (Dasgupta et al 2004). It is attributed to the

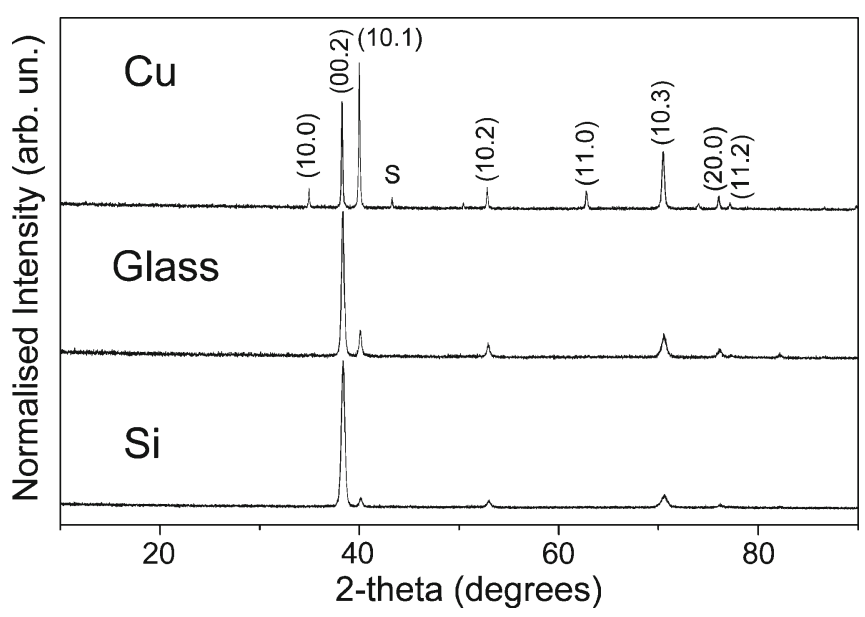

Figure 2. XRD patterns of Ti films deposited on different substrates. increased attraction of the charged sputtered species for the metallic substrates than those of the insulating substrates in the d.c. plasma.

Figure 3(a-c) shows the secondary electron micrographs of Ti coatings on the three substrates under investigation, i.e. $\mathrm{Si}$, glass and $\mathrm{Cu}$, respectively. The particles assume finely distributed spherical shapes measuring about 1-2 $\mu \mathrm{m}$ in diameter, in all three cases. However, analysis of figure 2 has shown that the Ti crystallite sizes are of the order of few tens
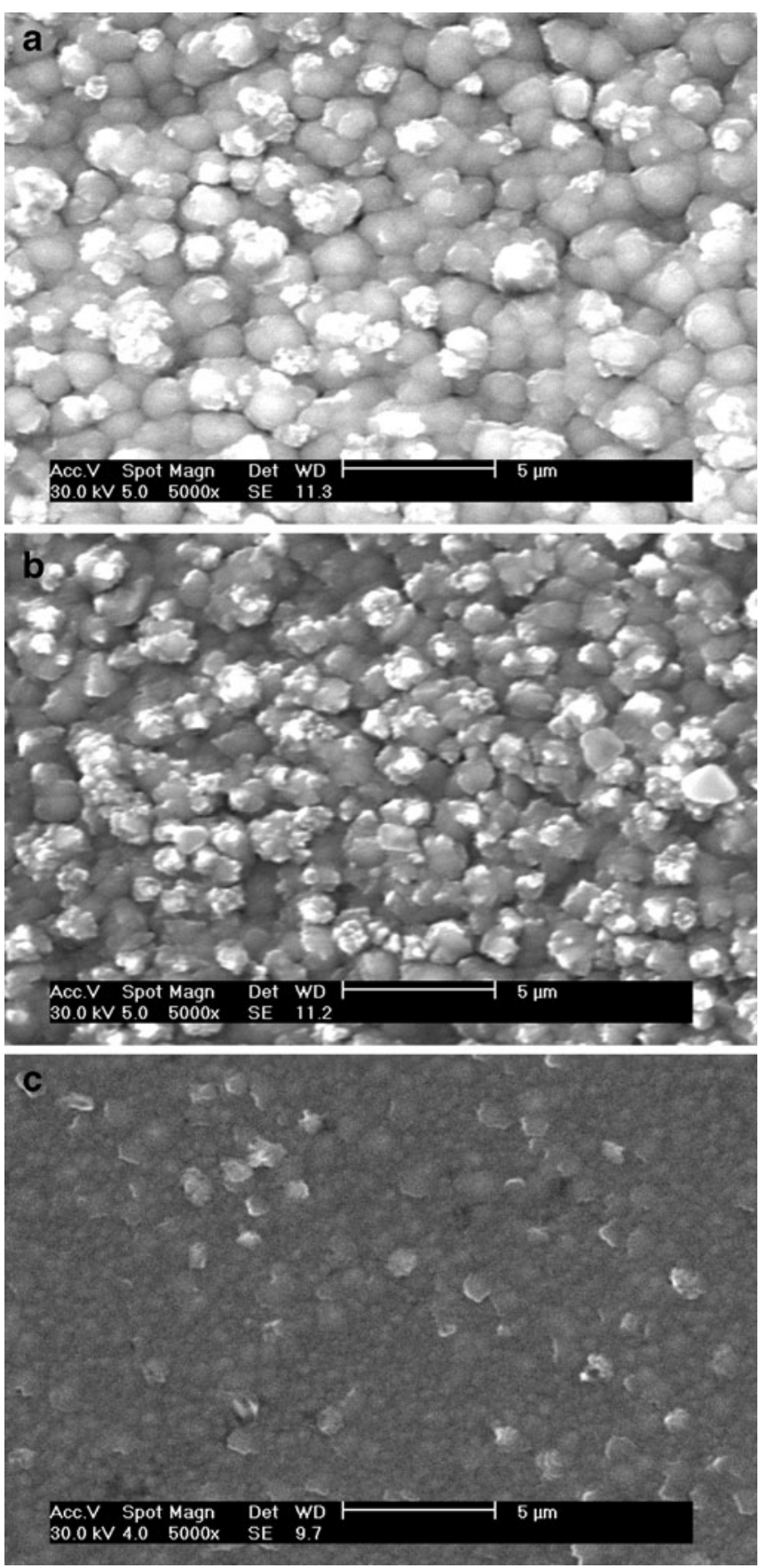

Figure 3. SEM image of Ti coating on different substrates: (a) Si, (b) glass and (c) $\mathrm{Cu}$. 
of nanometers. Therefore, it can be assumed that these particles are nanoclusters of Ti. The boundaries between the clustered regions are likely to be defect laden, sometimes even with voids or pores as is evident from these micrographs. It is also observed that the coatings on $\mathrm{Cu}$ are much smoother than on the other substrates. In the following discussions, we shall concentrate on the $\mathrm{Ti}$ coating on $\mathrm{Cu}$ substrate alone, given its technological importance.

Figure 4(a) shows the back scatter electron image of the coating-substrate interface. It is observed that the coating thickness is about $4.2 \mu \mathrm{m}$ which was found to be in agreement with the thickness measured by profilometer. The atomic number $(z)$ contrast back scatter electron image shows that there are no discontinuities observed at the interface. It is interesting to note that the Ti grows out in columnar fashion on the substrate. This feature reveals very important information about the growth mechanism of thin film. As per accepted models (Houben et al 1998), this kind of growth morphology is promoted when the adatom migration is low. With lower adatom mobility, the adatoms can nucleate and grow on preferential sites such as steps or artifacts on the substrate. Out of these nuclei, only a few grow along the direction of film thickness and hence appear columnar. The columnar structures are reported to be promoted when $T_{\mathrm{s}} / T_{\mathrm{m}} \leq 0.3$, where $T_{\mathrm{s}}$ is the substrate temperature and $T_{\mathrm{m}}$ the melting point of the material (Thornton 1977).
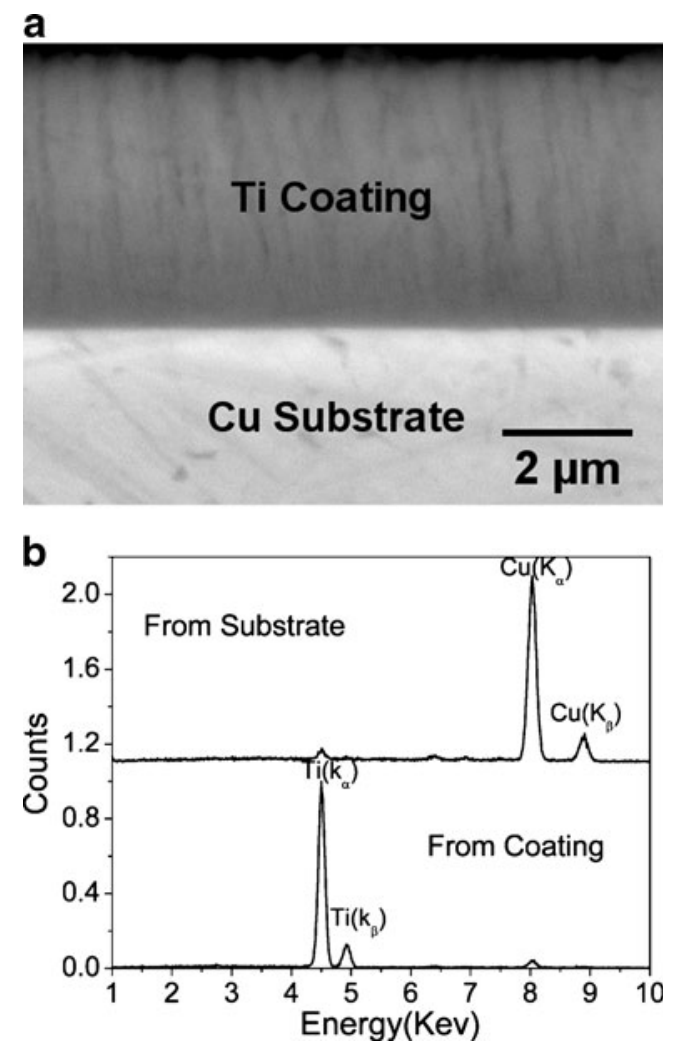

Figure 4. (a) Back scatter electron micrograph of the Ti coating on $\mathrm{Cu}$, and (b) energy dispersive X-ray spectra from the substrate and the coating.
Such growth mode is known to be strain tolerant (Toriz et al 1989), aids in obtaining complete coverage of the substrate (conformal coating) and provides good adhesion, an essential attribute for such coatings. From figure 3, it can be inferred that the columns are discontinuous and likely to have terminated, re-nucleated and grown again in a columnar fashion. A detailed TEM analysis presented in the latter section will further discuss on the morphology of the columnar structure.

Figure 4(b) shows the energy dispersive X-ray spectra from the substrate and the coating. Characteristic Xray emissions from the $\mathrm{Ti}$ coating and the $\mathrm{Cu}$ substrate are observed, while no impurities are detected. From these results it can be concluded that the coating is pure, there is no intermixing near the interface and that the Ti film grows in columnar fashion, which is perhaps discontinuous.

Figure 5(a) shows the selected area diffraction pattern from the coating. A ring pattern typical of polycrystalline materials is observed. Figure 5(b) shows the radially averaged intensity pattern obtained from the selected area diffraction pattern of figure 5(a). The inset of figure 5(b) shows deconvolution of the major peak into three overlapping peak profiles. Accordingly, presence of $(10 \cdot 0)_{\alpha},(00 \cdot 2)_{\alpha},(10 \cdot 1)_{\alpha}$, $(10 \cdot 2)_{\alpha},(11.0)_{\alpha},(10 \cdot 3)_{\alpha},(11.2)_{\alpha}$ and $(00 \cdot 4)_{\alpha}$ reflections (JCPDS 2003) is clearly identified and marked in the figure. This viewgraph resembles powder diffraction pattern of $\alpha$-Ti confirming that the coating is polycrystalline in nature. In addition, no signatures of $\mathrm{Cu}_{x} \mathrm{Ti}_{y}$ intermetallic compound, which are brittle phases and are detrimental to the interface strength of coatings, were observed. The observation of a polycrystalline $\alpha$-Ti for the film deposited on $\mathrm{Cu}$ is in agreement with the XRD spectra for this material shown in figure 3.

Figure 6(a) shows the dark field transmission electron micrograph using diffraction from $(00 \cdot 2)_{\alpha}$ plane of Ti. A number of columnar Ti crystals can be seen. The dark field transmission electron micrograph imaged under same conditions as in figure 6(a), but at higher magnification in order to reveal the interface in greater detail, is shown in figure 6(b). Bright columnar Ti crystals, with wide variation in length (30-250 nm) are observed. Owing to the proximity of the diffraction lines of $(00 \cdot 2)_{\alpha}$ and $(111)_{\mathrm{Cu}}$, the $\mathrm{Cu}$ substrate at the interface also appears bright. Besides, a distribution of bright marks is observed at the interface which may be attributed either to tiny Ti crystallites or inter-diffusion of $\mathrm{Cu}$ from the substrate.

From the analysis of figures 3 and 6, it is suggested that Ti nucleates and grows such that, a number of fine sized Ti crystallites appear, some of which favourably grow into columnar morphology. However, these columns grow in a cooperative manner bounded by a defective region. Therefore, the SEM columnar diameter represents a collection of a number of cooperatively grown columns and therefore, in the planar top view, they appear as nanoclusters.

Metallic films, especially refractory metals, deposited under the condition of limited atomic mobility usually 

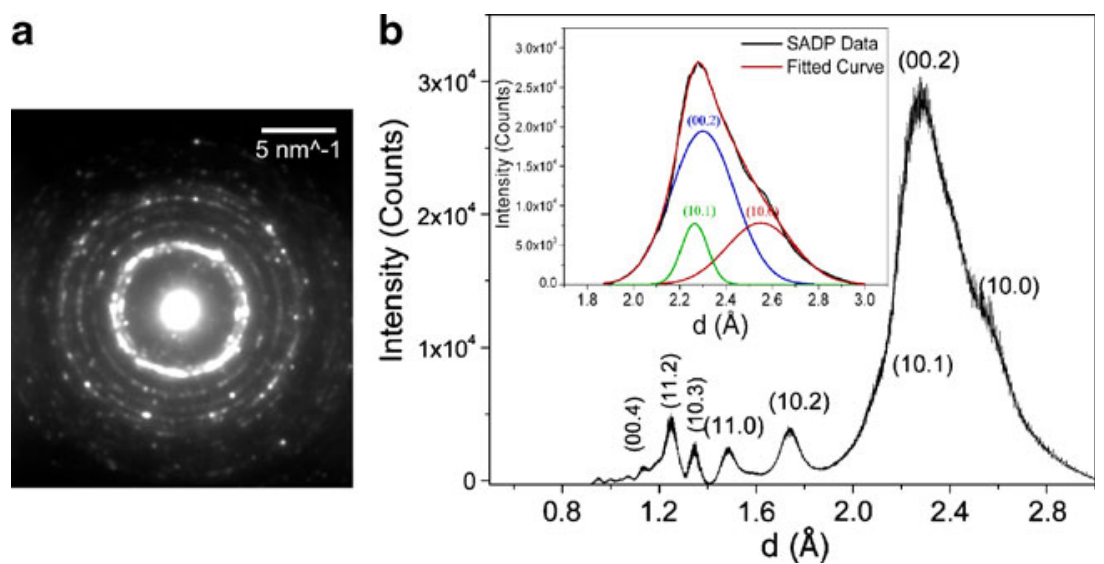

Figure 5. (a) SADP from the coating and (b) radially averaged intensity profile obtained from the SADP. Various diffraction peaks of $h c p$-Ti phase are identified. The inset shows the deconvolution of the major peak at $d=2 \cdot 3 \AA$ into three overlapping peak profiles.
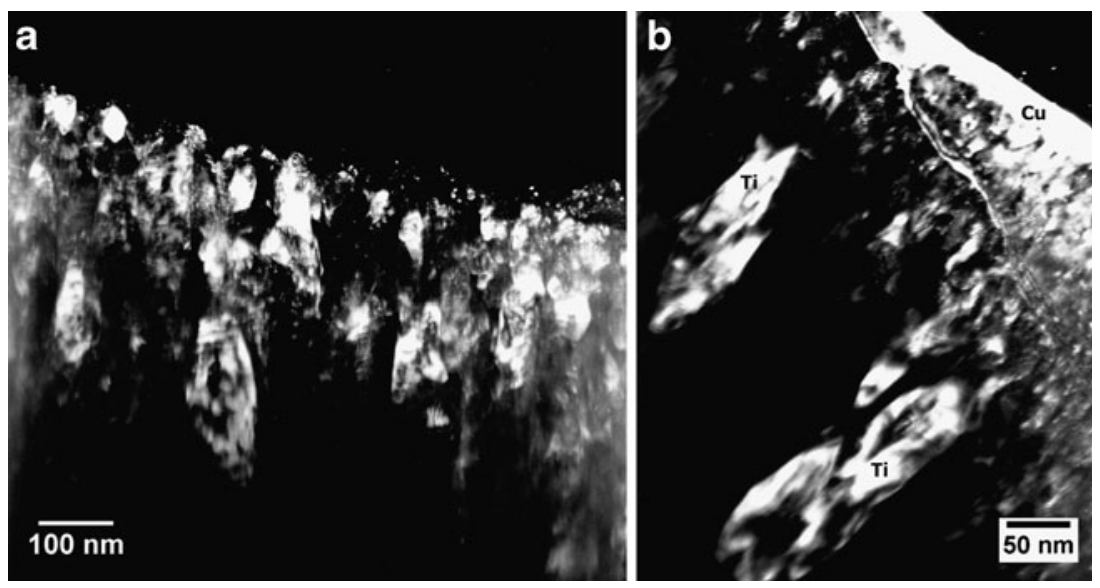

Figure 6. Dark field TEM micrograph of the Ti layer showing columnar Ti crystallites in (a) and the same at a higher magnification, revealing tiny Ti crystallites at the interface apart from a columnar Ti in (b).

exhibit columnar morphology (Dirksa et al 1992). In spite of the energetic particle bombardment of the growing films in the sputter deposition, the surface mobility of the adatoms is rather limited at a substrate temperature of $473 \mathrm{~K}$, as in the present work. This, in combination with the occurrence of geometric shadowing, usually results in films exhibiting a columnar microstructure. The columnar morphology is further influenced by the method of deposition, processing parameters (e.g. Ar pressure) and constituents of the film to be deposited. Under normal conditions, the sputterdeposited films have less-domed columns, i.e. have less vertical roughness, and develop less voiding at the column boundaries than the electron gun vapour deposited films (Dirksa et al 1992). The other parameter simultaneously influencing film structure, especially voids is the intrinsic stresses in sputter deposited films. Müller's (1987) molecular dynamic simulations has shown that increase of tensile stress in the film could cause inter-columnar voiding of the microstructure. Though the influence of some of the above parameters have not been studied systematically, it is clear that these parameters invariably produce porosity as seen by the SEM observation in the present work.

In order to ascertain if there is any inter-diffusion of elements across the interface, elemental X-ray mapping of an area around the interface using a $10 \mathrm{~nm}$ electron probe in TEM is shown in figure 7. Red and green colours in the figure represent $\mathrm{Cu}$ and Ti regions, respectively. A sharp interface indicates that there is no inter-diffusion of $\mathrm{Ti}$ or $\mathrm{Cu}$ at the interface. The above results also clearly show that the interface is free of voids, which aids adhesion.

In order to test adhesion of the $\mathrm{Ti}$ coating on $\mathrm{Cu}$ substrate, the material was subjected to cyclic heat treatments, as depicted in figure 8(a). As there were no decohesion or changes to the film morphology due to cyclic loading, the 


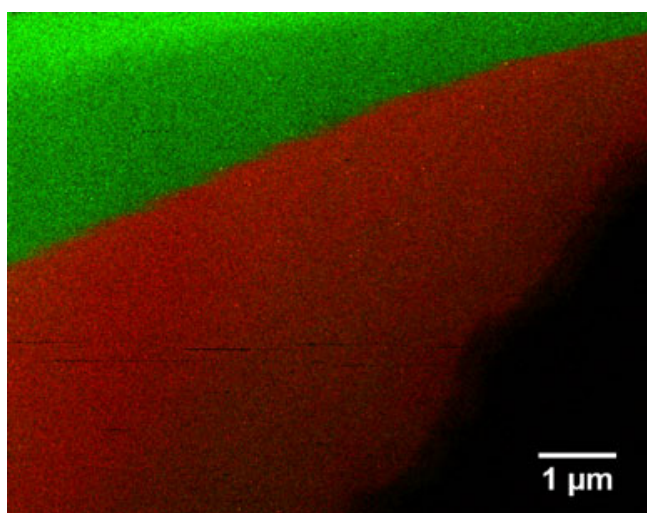

Figure 7. EDX map of the Ti coating on copper. Red and green colours correspond to $\mathrm{Cu}-\mathrm{K} \alpha$ and $\mathrm{Ti}-\mathrm{K} \alpha$, respectively.
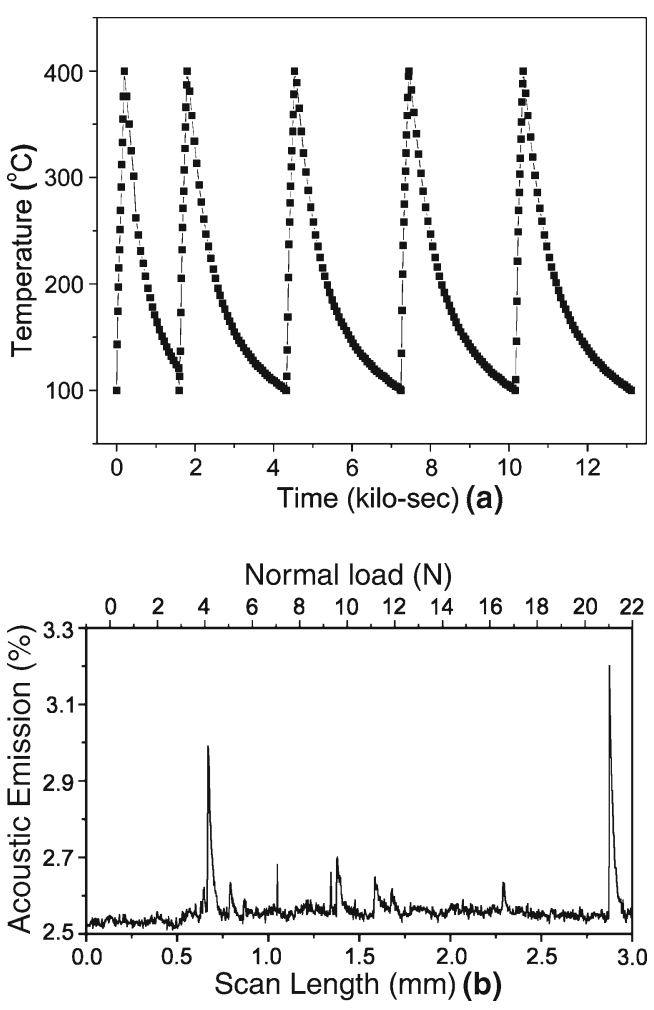

Figure 8. (a) Schematic of the heating and cooling cycle used for the adhesion test and (b) scratch test for Ti coating deposited on $\mathrm{Cu}$ substrate showing scan length and load as a function of acoustic signal.

coating was further subjected to scratch tests with a progressive load at least at 6 different locations. Acoustic signals as a function of the load were recorded. The first critical load to failure has been found to occur at 5.69, 6.24, 7.94, 4.45, $5 \cdot 19 \mathrm{~N}$. A typical plot showing acoustic signals obtained with a progressive load up to $20 \mathrm{~N}$ on the sample is shown in figure 8(b). The figure shows first critical load to failure of $4.5 \mathrm{~N} \pm 2 \mathrm{~N}$. The delamination rate of the coatings is significant at higher loads, where acoustic signal peaks are quite frequently seen. The coatings seem to fail in a cohesive manner as there are cluster of acoustic signals at higher applied loads. However, the overall adhesion of the coatings with copper is quite satisfactory for technological applications.

\section{Summary}

The growth of Ti coatings on glass, silicon (100) and oxygen free high purity copper deposited by pulsed d.c. magnetron sputtering has been investigated. The results indicated that the coatings on $\mathrm{Cu}$ were polycrystalline and smooth, while the coatings on glass and silicon are textured. Ti coatings of about $4 \mu \mathrm{m}$ thickness on $\mathrm{Cu}$ substrate were investigated in detail using electron microscopy and scratch indentation techniques for its interface quality for application in nuclear industry. Scanning electron microscopy and transmission microscopy results showed that the interface was free from voids and secondary phases, although pores have been observed on the surface of the films. Energy dispersive $\mathrm{X}$-ray spectroscopy results showed that there was no intermixing of elements at the interface between the coating and the substrate. The scratch test confirmed that the adhesion of the coating with copper was also quite satisfactory. The electron microscopy results coupled with XRD studies helped by formulating a growth model for the Ti coatings.

\section{Acknowledgements}

The authors would like to acknowledge Dr CR Venkatasubramani, Nuclear Chemistry Section, Chemistry Group, for very useful discussions. The authors would also like to express their gratitude to Dr T Jayakumar, Director, MMG, Dr PR Vasudeva Rao, Director, Chemistry Group and Dr Baldev Raj, Director, IGCAR, for their constant encouragement and support during the course of this work.

\section{References}

Baldev Raj, Kamachi Mudali U, Jayakumar T, Kasiviswanathan K V and Natarajan R 2000 Sadhana 25519

Bateni M R, Ashrafizadeh F, Szpunar J A and Drew R A L 2002 Wear 253626

Csikai J 1987 CRC Handbook of Fast Neutron Generators 13

Dasgupta A, Kuppusami P, Lawrence F, Raghunathan V S, Antony Premkumar P and Nagaraja K S 2004 Mater. Sci. Eng. A374 362

Destefani J D 1990 Introduction to titanium and titanium alloys, in Metals handbook (ASM International) $10^{\text {th }}$ ed., Vol. 2, pp. 586591

Dirksa A G, Woltersa R A M and De Veirmana A E M 1992 Thin Solid Films 208181

Elangovan T, Kuppusami P, Thirumurugesan R, Mohandas E and Mangalaraj D 2009 J. Nanosci. Nanotechnol. 95436

Elangovan T, Kuppusami P, Thirumurugesan R, Ganesan V, Mohandas E and Mangalaraj D 2010 Mater. Sci, Eng. B167 17

Eylon D 1990 Titanium and titanium alloy castings, in ASM metals handbook (ASM International) Vol. 2, p. 634 
Houben L, Luysberg M, Hapke P, Carius R, Finger F and Wagner H 1998 Philos. Mag. A77 1447

JCPDS-ICDD Database 2003 File No. 44-1294

Jin Y, Wu W, Li L, Chen J, Zhang J, Zuo Y and Fu J 2009 Appl. Surf. Sci. 2554673

Jung M J, Nam K H, Shaginyan L R and Han J G 2003 Thin Solid Films $\mathbf{4 3 5} 145$

Kamachi Mudali U, Dayal R K and Gnanamoorthy J B 1993 J. Nucl. Mater. 20373

Kamachi Mudali U, Dayal R K and Gnanamoorthy J B 1995 J. Mater. Engg. Perform. 4756

Lee S K et al 2009 Appl. Radiat. Isotopes 671234

Ludewigt B A, Wells R P and Reijonen J 2007 Nucl. Instrum. Meth. Phys. Res. B261 830

Matsunami N, Yamamura Y, Ltilkwa Y, Itoh N, Kazumata Y, Miyagawa S, Morita K, Shimizu R and Tawara H 1984 Atomic Data Table 311
Müller K -H 1987 J. Appl. Phys. 621796

Musil J, Vlcek J, Jezek V, Benda M, Kubásek M and Soukup L 1996 Vacuum 47871

Neubauera E, Eisenmenger-Sittnera C, Bangerta H and Korb G 2003 Vacuum 71293

Niinomi M 1998 Mater. Sci. Engg. A243 231

Oya T and Kusano E 2009 Thin Solid Films 5175837

Ruder A and Itzhak D 1982 Thin Solid Films 97339

Ruder A and Itzhak D 1983 Vacuum 33231

SGTE 2004 SGTE alloy databases for Ti-Cu binary system (revised) Thornton J A 1977 Ann. Rev. Mater. Sci. 7239

Toriz F C, Thankker A B and Gupta S K 1989 Surf. Coat. Technol. 39/40 161

Vieira R A and Nono M C A 2004 J. Mater. Res. 7479

Zhang E, Xu L and Yang K 2005 Scr. Mater. 53523

Zhang L, Shi L Q, He Z J, Zhang B, Lu Y F, Liu A and Wang B Y 2009 Surf. Coat. Technol. 2033356 